\title{
THE PREDICTED BEHAVIOR OF GRIESGLETSCHER, WALLIS, SWITZERLAND, AND ITS POSSIBLE THREAT TO A NEARBY DAM (Abstract only)
}

by

\section{Robert Bindschadler}

(Oceans and Ice Branch, Code 912.1, NASA/Goddard Space Flight Center, Greenbelt, Maryland 20771, U.S.A.)

ABSTRACT

The behavior of Griesgletscher, Switzerland, is studied by application of a numerical model of temperate glacier flow. The analysis addresses the possible danger posed to a hydroelectric dam which is $600 \mathrm{~m}$ from the calving terminus of the glacier. Model parameters are adjusted to fit data collected over eleven years. A calving law relating the calving flux to the water depth at the front provides a good fit of the data. Assuming a continuation of the present climate, the terminus is predicted to retreat $200 \mathrm{~m}$ over the next forty years, followed by an advance of
$150 \mathrm{~m}$ lasting several centuries. Numerous experimental climate alterations show that the dam will not be threatened by short-term climatic changes. A long-term mass-balance increase of $0.12 \mathrm{~m}$ of ice per year (or a drop of $0.2^{\circ} \mathrm{C}$ in mean annual air temperature) would be sufficient to fill the reservoir with ice. With an additional increase of $0.07 \mathrm{~m}$ of ice per year the terminus would reach the dam. Data from the 1923 and 1850 moraines are used to suggest lowerbound estimates of temperature changes $(-0.4$ and $-0.6^{\circ} \mathrm{C}$ respectively) during these periods of glacial maxima.

\section{TWO CALVING LAWS FOR GROUNDED ICEBERG- CALVING GLACIERS (Abstract only)}

by

\section{S. Brown, W. G. Sikonia, Austin Post, L. A. Rasmussen and M. F. Meier \\ (U.S. Geological Survey, Tacoma, Washington 98402, U.S.A.)}

\section{ABSTRACT}

Prediction of the future retreat of Columbia Glacier, Alaska, required a calving law for the boundary condition at the terminus. Qualitative observations on the variations of all major icebergcalving glaciers of Alaska suggest that calving is high whenever glaciers terminate in deep water, and greatly reduced whenever they terminate in shallow water. Calving relations were investigated based on calculations of calving speed, defined as the volume rate of iceberg discharge from the terminus divided by the cross-sectional area of the terminus. The calving speed was determined for 12 glaciers for which measurements of glacier speed, advance and retreat rates, and other variables were obtained. To extend the range of data, four additional periods of rapid retreat were examined. Values for the terminus characteristics of water depth, cliff height, and thickness of the terminus, averaged over the width of the glacier and over a year, were then examined in relation to the calculated speeds of calving. A statistical analysis to determine the form and coefficients of an empirical calving relation that approximates the data shows that calving speed is best fitted by a simple proportionality to average water depth at the terminus:

$$
\bar{v}_{\mathrm{C}}=c \bar{h}_{\mathrm{w}} \text {, }
$$

where $\bar{v}_{c}$ is the calving speed and $\bar{h}_{W}$ the water depth, both averaged over the width and over a year, and $c$ a constant of proportionality. This gives a variance reduction fraction (similar to the coefficient of determination $r^{2}$ ) of 0.90 .

To investigate seasonal changes in calving, data based on shorter time intervals were obtained at the head of embayments from Columbia Glacier. At intervals of approximately two months, the following expression fits intra-yearly calving at Columbia Glacier:

$$
v_{c}=a D^{b} h_{u}^{c},
$$

where $D$ is the meltwater discharge from the glacier, $h_{u}$ is the height of the ice column unsupported by water buoyancy, a, b, c are constants, and $v_{c}$ and $h_{u}$ are evaluated at the embayment head. D was determined by correlation with a nearby glacial stream, and $h_{u}=h-h_{w} \rho_{W} / \rho_{i}$, where $h$ is glacier thickness and $\rho_{j}$ and $\rho_{W}$ the densities of $i c e$ and water. Best-fit values of $b$ and $c$ are approximately 0.5 and -2 , respectively. This yields a variance reduction fraction $r^{2}$ of 0.83 .

Equation (2) does not fit data averaged over a year and over the width of the glacier and Equation (1) does not fit data obtained over shorter periods at the head of the embayment. Although the two equations are different in form, for similar or average values of $D$ and $h-h_{w}$ (ice-cliff height), they give approximately similar results over the present range of the geometry of the terminus of Columbia Glacier. Whether this will be true after rapid retreat begins remains to be seen. 